\title{
Thermodynamic evaluation of $\mathrm{LiCl}-\mathrm{KCl}-\mathrm{PuCl}_{3}$ system
}

\author{
Wentao Zhou* and Jinsuo Zhang \\ Nuclear Engineering Program, Department of Mechanical and Aerospace Engineering \\ The Ohio State University, Columbus OH 43210, USA \\ *Corresponding author. Email: zhou.1174@osu.edu
}

\begin{abstract}
The present study focuses on developing the phase diagram of $\mathrm{LiCl}-\mathrm{KCl}-\mathrm{PuCl}_{3}$ system based on the CALPHAD (CALculation of PHase Diagram) method. Sub-binary systems of LiCl-KCl, $\mathrm{LiCl}-\mathrm{PuCl}_{3}$, and $\mathrm{KCl}-\mathrm{PuCl}_{3}$ were developed first by optimizing the Gibbs energy parameters according to the experimental data from literature using the two-sublattice model. Then the enthalpy of mixing of the $\mathrm{LiCl}-\mathrm{KCl}-\mathrm{PuCl}_{3}$ system was estimated, to explore the ternary interactions, using an empirical correlation derived from the surrounded-ion model for the asymmetric salt system due to the scarcity of available data for the ternary system. Based on the phase diagram developed, the solubility of $\mathrm{PuCl}_{3}$ in the eutectic $\mathrm{LiCl}-\mathrm{KCl}$ melt at different temperatures was obtained, as well as the Gibbs energy of formation of $\mathrm{PuCl}_{3}$ in the salt as a function of $\mathrm{PuCl}_{3}$ concentration. The present study extends the experimental data for dilutions to concentrated solutions for which no experimental data have been well reported.
\end{abstract}

Keywords: $\mathrm{LiCl}-\mathrm{KCl}-\mathrm{PuCl}_{3}$, Phase diagram, CALPHAD, Two-sublattice model

\section{Introduction}

Pyroprocessing in $\mathrm{LiCl}-\mathrm{KCl}$ molten salt has been developed as an alternative to the PUREX process to separate the uranium and other actinides from used nuclear fuels $[1,2,3]$, which will reduce the volume of radioactive waste and recycle the useful fuel. Electrorefiner is the key step in pyroprocessing, where uranium electrodeposits onto a solid cathode selectively by controlling the applied current, then the residual uranium, plutonium, and other minor actinides are collected from the salt as a group [4]. As more and more fuel is reprocessed, the composition of molten salt changes, which will alter the thermodynamic properties of the system and cause adjustments to the operation conditions to be needed [5,6,7]. In order to optimize the system design and operate it safely, thermodynamic assessment of actinides and lanthanides in LiCl-KCl molten salt is significantly needed. Even though several systems have been assessed, such as $\mathrm{LiCl}-\mathrm{KCl}-\mathrm{CeCl}_{3}[8,9]$ and $\mathrm{LiCl}-\mathrm{KCl}-\mathrm{UCl}_{3}[10]$, as one of the major actinides in pyroprocessing, $\mathrm{PuCl}_{3}$ in $\mathrm{LiCl}-\mathrm{KCl}$ has not been evaluated.

In the present work, thermodynamic properties of $\mathrm{LiCl}-\mathrm{KCl}-\mathrm{PuCl}_{3}$ are being considered and evaluated. Two-sublattice model for ionic liquid was applied to $\mathrm{LiCl}-\mathrm{KCl}, \mathrm{LiCl}-\mathrm{PuCl}_{3}$, and $\mathrm{KCl}-$ 
$\mathrm{PuCl}_{3}$ binary systems primarily to model their Gibbs energies. The experimental data used includes the phase information and enthalpy of mixing from literature. However, for the LiCl$\mathrm{KCl}-\mathrm{PuCl}_{3}$ ternary system, previous studies are limited in electrochemical measurements with dilute solution. These data could be used but not enough to evaluate the ternary interactions in the system. As a supplementary, an empirical correlation to estimate the enthalpy of mixing for asymmetric salt system that has been successfully used in the $\mathrm{LiCl}-\mathrm{KCl}-\mathrm{UCl}_{3}$ system [10] was applied to calculate the enthalpy of mixing of the $\mathrm{LiCl}-\mathrm{KCl}-\mathrm{PuCl}_{3}$. These data combined with the results from binary systems were used as input to assess the thermodynamic equilibria of the $\mathrm{LiCl}-\mathrm{KCl}-\mathrm{PuCl}_{3}$ system. After that, the solubility and Gibbs energy of formation of $\mathrm{PuCl}_{3}$ in the typical molten $\mathrm{LiCl}-\mathrm{KCl}$ used in pyroprocessing were derived from the optimized results.

\section{Thermodynamic modelling}

Phase diagram development is the process to find the stable or metastable phases and phase boundaries. All these properties could be reflected by the Gibbs energy of the system [11]. For example, the global minimum Gibbs energy corresponds to stable phase and local minimum Gibbs energy to the metastable phase. Also, when two phases coexist, the chemical potential of a species in these two phases should be the same

$$
\mu_{i}^{\varphi 1}=\left(\frac{\partial G_{t}^{\varphi 1}}{\partial n_{i}^{\varphi 1}}\right)_{n_{j \neq i}, p, T}=\mu_{i}^{\varphi 2}=\left(\frac{\partial G_{t}^{\varphi 2}}{\partial n_{i}^{\varphi 2}}\right)_{n_{j \neq i}, p, T}
$$

Eq. 1

where $\mu_{i}^{\varphi j}$ and $n_{i}^{\varphi j}$ are the chemical potential and mole number of $i$ in phase $\varphi j$, respectively. $G_{t}^{\varphi j}$ is the total Gibbs energy of phase $\varphi j . p$ and $T$ are the pressure and absolute temperature, respectively. Generally, for the solution phase of a ternary system with components of 1-2-3, the molar Gibbs energy could be expressed by [12]

$$
\begin{aligned}
G_{m} & =\sum_{i=1}^{3} x_{i} G_{i}^{0}+R T \sum_{j=1}^{3} x_{j} \ln x_{j}+G_{m}^{e x} \\
& =\sum_{i=1}^{3} x_{i} G_{i}^{0}+R T \sum_{j=1}^{3} x_{j} \ln x_{j}+\left(G_{m, 12}^{e x}+G_{m, 23}^{e x}+G_{m, 13}^{e x}+G_{m, 123}^{e x}\right)
\end{aligned}
$$

where $G_{i}^{0}$ is the standard molar Gibbs energy of $i . G_{m}^{e x}$ is the molar excess Gibbs energy including the contributions from all sub-binary systems 1-2, 2-3, and 1-3 as well as the ternary system 1-2-3 in the solution. $x_{i}$ is the mole fraction of $i$ in the solution phase, $\mathrm{R}$ is the gas constant, and $\mathrm{T}$ is the temperature in kelvin. Therefore, in order to calculate the phase diagram, a Gibbs energy model to describe the solution of the system should be built first. 
In the present work, a two-sublattice model [13][14] was applied to describe the excess Gibbs energy of liquid. The model separates anions and cations into different sublattices. There are two intermediate compounds in $\mathrm{LiCl}-\mathrm{KCl}-\mathrm{PuCl}_{3}$ system, $\mathrm{K}_{2} \mathrm{PuCl}_{5}$ and $\mathrm{K}_{3} \mathrm{PuCl}_{6}$ [15] and a previous study shows $\mathrm{PuCl}_{6}^{3-}$ prevails in $\mathrm{Pu}(\mathrm{III})$-containing molten salt [16]. Accordingly, here $\mathrm{K}_{3} \mathrm{PuCl}_{6}$ is treated as a neutral species in anionic sublattice to deal with the short-range ordering. Now the model is indicated by

$$
\left(\mathrm{K}^{+}, \mathrm{Li}^{+}, \mathrm{Pu}^{3+}\right)_{p}:\left(\mathrm{Cl}^{-}, \mathrm{K}_{3} \mathrm{PuCl}_{6}\right)_{q}
$$

The parenthesis represents different lattices and the colon is used to separate them. In every parenthesis, there is a constituent array resided in the sub-lattice. $p$ and $q$ are the site numbers in the corresponding lattice and given by

$$
p=y_{C l^{-}}
$$

And

$$
q=y_{K^{+}}+y_{L^{+}}+3 y_{P u^{3+}}
$$

where $y_{i}$ is the site fraction of a particular species $i$ on the corresponding sublattice. The molar Gibbs energy of liquid phase now is

$$
\begin{aligned}
& G_{m}^{L i q .}=y_{\mathrm{Li}^{+}} y_{\mathrm{Cl}^{-}}{ }^{0} G_{\mathrm{Li}^{+}: \mathrm{Cl}^{-}}^{\mathrm{Liq} .}+y_{\mathrm{K}^{+}} y_{\mathrm{Cl}^{-}}{ }^{0} G_{\mathrm{K}^{+}: \mathrm{Cl}^{-}}^{\mathrm{Liq} .}+y_{\mathrm{Pu}^{3+}} y_{\mathrm{Cl}^{-}}{ }^{0} G_{\mathrm{Pu}^{+}: \mathrm{Cl}^{-}}^{\mathrm{Liq} .} \\
& +{ }^{0} G_{K_{3} P u C l_{6}}^{L i q .}+R T\left[p\left(y_{L^{+}} \ln y_{L^{+}}+y_{K^{+}} \ln y_{K^{+}}+y_{P^{3+}} \ln y_{P u^{3+}}\right)\right. \\
& \left.q\left(y_{C l^{-}} \ln y_{\mathrm{Cl}^{-}}+y_{\mathrm{K}_{3} \mathrm{PuCl}_{6}} \ln y_{\mathrm{K}_{3} \mathrm{PuCl} \mathrm{l}_{6}}\right)\right]+{ }^{E} G_{m}^{\mathrm{Liq} .}
\end{aligned}
$$

where ${ }^{0} G_{\mathrm{Li}^{+}: \mathrm{Cl}^{-}}^{\mathrm{Liq}},{ }^{0} G_{\mathrm{K}^{+}: \mathrm{Cl}^{-}}^{\mathrm{Liq}}{ }^{0} G_{\mathrm{Pu}^{3+}: \mathrm{Cl}^{-}}^{\mathrm{Liq}},{ }^{0} G_{\mathrm{K}_{3} P u C l_{6}}^{\mathrm{Liq}}$ are the standard molar Gibbs energy of $\mathrm{LiCl}, \mathrm{KCl}$, $\mathrm{PuCl}_{3}$, and $\mathrm{K}_{3} \mathrm{PuCl}_{6}$ in liquid status, respectively. ${ }^{E} G_{m}^{\text {Liq. }}$ is the molar excess Gibbs energy. In the manner of Muggianu formalism [17], it was given by

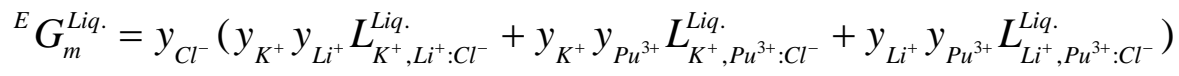

$$
\begin{aligned}
& +y_{\mathrm{Cl}^{-}} y_{\mathrm{K}_{3} \mathrm{PuCl}_{6}}\left(y_{\mathrm{K}^{+}} L_{\mathrm{K}^{+}: \mathrm{Cl}^{-}, \mathrm{K}_{3} \mathrm{PuCl}_{6}}^{\mathrm{Liq.}}+y_{\mathrm{Li}^{+}} L_{\mathrm{Li}^{+}: \mathrm{Cl}^{-}, \mathrm{K}_{3} \mathrm{PuCl}_{6}}^{\mathrm{Liq}}+y_{\mathrm{Pu}^{3+}} y_{\mathrm{K}_{3} \mathrm{PuCl}_{6}} L_{\mathrm{Pu}^{3+}: \mathrm{Cl}^{-}, \mathrm{K}_{3} \mathrm{PuCl} l_{6}}^{\mathrm{Liq}}\right) \\
& +y_{\mathrm{Cl}^{-}} y_{\mathrm{K}_{3} \mathrm{PuCl}_{6}}\left(y_{\mathrm{K}^{+}} y_{\mathrm{Li}^{+}} \mathrm{L}_{\mathrm{K}^{+}, \mathrm{Li}^{+}: \mathrm{Cl}^{-}, \mathrm{K}_{3} \mathrm{PuCl}_{6}}^{\mathrm{Liq}}+y_{\mathrm{K}^{+}} y_{\mathrm{Pu}^{3+}} \mathrm{Liq.}_{\mathrm{K}^{+}, \mathrm{Pu}^{3+}: \mathrm{Cl}^{-}, K_{3} \mathrm{PuCl}}\right. \\
& \left.+y_{\mathrm{Li}^{+}} y_{\mathrm{Pu}^{3+}} \mathrm{Li}_{i^{+}, \mathrm{Pu}^{3+}: \mathrm{Cl}^{-}, \mathrm{K}_{3} P \mathrm{PCl}_{6}}^{\mathrm{Liq}}\right)+y_{\mathrm{K}^{+}} y_{\mathrm{Li}^{+}} y_{\mathrm{Pu}^{3+}} y_{\mathrm{Cl}^{-}}\left(L_{\mathrm{K}^{+}, \mathrm{Li}^{+}, \mathrm{Pu}^{3+}: \mathrm{Cl}^{-}}^{\mathrm{Liq}}\right. \\
& \left.+y_{K_{3} \mathrm{PuCl}_{6}} L_{\mathrm{K}^{+}, \mathrm{Li}^{+}, \mathrm{Pu}^{3+}: \mathrm{Cl}^{-}, \mathrm{K}_{3} \mathrm{PuCl}_{6}}^{\mathrm{Liq}}\right)
\end{aligned}
$$


These interaction parameters $L$ for both binary and ternary interactions could be expressed as concentration and temperature dependent. For example, binary interaction parameter $L_{\mathrm{K}^{+}, \mathrm{Pu}^{3+}: \mathrm{Cl}^{-}}^{\mathrm{Liq}}$ can be expanded as a Redlich-Kister polynomial [18]

$$
L_{K^{+}, P u^{3+}: C l^{-}}^{L i q .}=\sum_{v=0}^{n v} L_{K^{+}, P u^{3+}: C l^{-}}^{L i q}\left(y_{K^{+}}-y_{P u^{3+}}\right)^{v}
$$

And ternary one, for example, can be

$$
L_{L i^{+}, K^{+}, P u^{3+}: C l^{-}}^{L i q .}=y_{L i^{+}} L_{L i^{+}: C l^{-}}+y_{K^{+}} L_{K^{+}: C l^{-}}+y_{P u^{3+}} L_{P u^{3+}: C l^{-}}
$$

Then linear dependence on temperature is applied to these parameters like

$$
{ }^{v} L=a_{v}+b_{v} T
$$

$a_{v}$ and $b_{v}$ are the parameters that will be optimized during the calculation. Since there are no heat capacity data for the intermediate compounds $\mathrm{K}_{2} \mathrm{PuCl}_{5}$ and $\mathrm{K}_{3} \mathrm{PuCl}_{6}$, their standard Gibbs energies are written according to Neumann-Kopp rule [19] as

$$
{ }^{0} G_{K_{m} P u_{n} C_{m+3 n}}^{\text {state }}=m^{0} G_{K C l}^{\text {state }}+n^{0} G_{P u C l_{3}}^{\text {state }}+A+B T
$$

where "state" stands for liquid or solid. A and B are variables related to the enthalpy and entropy of formation of the intermediate compound $\mathrm{K}_{\mathrm{m}} \mathrm{Pu}_{\mathrm{n}} \mathrm{Cl}_{\mathrm{m}+3 \mathrm{n}}$, respectively. These values were optimized according to experimental data.

The only solid solution considered in the $\mathrm{LiCl}-\mathrm{KCl}-\mathrm{PuCl}_{3}$ system is the $\mathrm{LiCl}-\mathrm{KCl}$ mutual terminal solution that is less than 5 at\% reported by Ghosh [10]. The solid solution is also described by two-sublattice model as

$$
\left(\mathrm{Li}^{+}, \mathrm{K}^{+}\right)_{1}:\left(\mathrm{Cl}^{-}\right)_{1}
$$

The molar Gibbs energy is

$$
G_{m}^{S}=y_{K^{+}}{ }^{0} G_{K^{+}: C l^{-}}^{S}+y_{L i^{+}}{ }^{0} G_{L^{+}: C l^{+}}^{S}+R T\left(y_{K^{+}} \ln y_{K^{+}}+y_{L^{+}} \ln y_{L i^{+}}\right)+{ }^{E} G_{m}^{S}
$$

And excess Gibbs energy is 


$$
{ }^{E} G_{m}^{S}=y_{L i^{+}} y_{K^{+}}{ }^{v} L_{L i^{+}, K^{+}: C l^{-}}^{S}=y_{L i^{+}} y_{K^{+}} \sum_{v=0}^{n}{ }^{v} L_{L i^{+}, K^{+}: C l^{-}}^{S}\left(y_{L i^{+}}-y_{K^{+}}\right)^{v} \quad \text { Eq. } 12
$$

\section{Database for the $\mathrm{LiCl}-\mathrm{KCl}-\mathrm{PuCl}_{3}$ system}

For developing the ternary phase diagram based on CALPHAD, experimental data for all the binary systems $\left(\mathrm{LiCl}-\mathrm{KCl}, \mathrm{LiCl}-\mathrm{PuCl}_{3}, \mathrm{KCl}-\mathrm{PuCl}_{3}\right)$ and the ternary system are needed. In this section, the database was developed based on previous experimental data.

\subsection{Binary systems}

The LiCl-KCl system has been widely studied. Phase boundary information was investigated by Richards [20], Aukrust [21], Korin [22], and Basin [23] with the methods of heating curves, cooling curves, calorimetric measurements and oscillation phase analysis. Hersh [24] studied the enthalpy of mixing at the temperature of $1013 \mathrm{~K}$. Recently Ghosh [10] evaluated the LiCl-KCl system with terminal solubility and demonstrated by experiments that the mutual solubility is less than 5 at\%. However, there are only a few studies on $\mathrm{LiCl}-\mathrm{PuCl}_{3}$ and $\mathrm{KCl}-\mathrm{PuCl}_{3}$. Bjorklund and co-workers [25] studied the phase equilibria of the $\mathrm{LiCl}^{-\mathrm{PuCl}_{3}}$ binary system and reported it to be a simple eutectic system without any solid solution or intermediate compounds. The eutectic point occurs at $28 \% \mathrm{PuCl}_{3}$ with a temperature of $734 \mathrm{~K}$. The phase diagram of $\mathrm{KCl}-$ $\mathrm{PuCl}_{3}$ is a little more complex compared to the other two binary systems since two intermediate compounds were reported [15]: $\mathrm{K}_{3} \mathrm{PuCl}_{6}$ and $\mathrm{K}_{2} \mathrm{PuCl}_{5} . \mathrm{K}_{3} \mathrm{PuCl}_{6}$ melts congruently at $685^{\circ} \mathrm{C}$ and the peritectic point related to $\mathrm{K}_{2} \mathrm{PuCl}_{5}$ melting appears at $35 \% \mathrm{PuCl}_{3}$ with a temperature of $611^{\circ} \mathrm{C}$.

\subsection{Ternary system}

Even though no reports about the phase diagram or enthalpy have been found about the LiCl$\mathrm{KCl}-\mathrm{PuCl}_{3}$ system, a variety of experimental measurements have been done to explore the electrochemical behaviors of $\mathrm{PuCl}_{3}$ in $\mathrm{LiCl}-\mathrm{KCl}$ eutectic salt. By emf (electromotive force) measurement, Roy [26] studied the Gibbs energy of formation of $\mathrm{PuCl}_{3}$ in a temperature range of $673 \mathrm{~K}$ to $773 \mathrm{~K}$. This study was carried out using many different $\mathrm{PuCl}_{3}$ mole fractions from $x_{\mathrm{PuCl}_{3}}=1.91 \times 10^{-5}$ to $x_{\mathrm{PuCl}_{3}}=1.58 \times 10^{-3}$. Sakamura [27] reported the standard potential of $\mathrm{PuCl}_{3}$ at $723 \mathrm{~K}$ against $\mathrm{Ag} / \mathrm{AgCl}$ with $1 \mathrm{wt} \% \mathrm{AgCl}$ by varying the composition from $x_{\mathrm{PuCl}_{3}}=3.54 \times 10^{-5}$ to $x_{\mathrm{PuCl}_{3}}=1.03 \times 10^{-3}$ using cyclic voltammetry. Another study [28] was also carried out by them using emf method with $x_{\mathrm{PuCl}_{3}}=2.9 \times 10^{-4}-2.35 \times 10^{-3}$ at the temperatures from $673-773 \mathrm{~K}$. Shirai [29] conducted experiments by cyclic voltammetry with temperatures from $723 \mathrm{~K}$ to $823 \mathrm{~K}$ to explore the redox potential of $\mathrm{Pu}^{3+} / \mathrm{Pu}$. Both Mo solid electrode and Bi liquid electrode were applied into the weight percent of $w_{\mathrm{PuCl}_{3}}=0.46 \%-0.87 \%$. They concluded the redox potential is 
more positive with the liquid $\mathrm{Bi}$ electrode than with the solid electrode. Shirai [30] also investigated the Gibbs energy of formation of $\mathrm{PuCl}_{3}$ at the temperature range between $723 \mathrm{~K}$ and $823 \mathrm{~K}$ but only at one composition of $x_{\mathrm{PuCl}_{3}}=1.4 \times 10^{-3}$. Serp [31] measured the apparent standard potential and Gibbs energy of formation of $\mathrm{PuCl}_{3}$ in the range of $x_{\mathrm{PuCl}_{3}}=1.662-3.03 \times 10^{-3}$ by cyclic voltammetry and chronopotentiometry method and then derived the activity coefficient at temperatures of 733,773 , and $823 \mathrm{~K}$. They found the values are sensitive to the supercooled data. They obtained activity coefficient of $\gamma_{\mathrm{PuCl}_{3}}=3.5-7.9 \times 10^{-3}$ under UEA-TDP data source [32] but $\gamma_{\mathrm{PuCl}_{3}}=9.5-16 \times 10^{-3}$ under f-MPD data source [33] when other conditions were kept the same. Using the similar method, Masset [34] studied the Gibbs energy of formation of $\mathrm{PuCl}_{3}$ and calculated the activity coefficient with the values of $\gamma_{\mathrm{PuCl}_{3}}=3.5-7.9 \times 10^{-3}$ at the temperature range from $733 \mathrm{~K}$ to $823 \mathrm{~K}$. These review data were inputted to the Gibbs energy model to evaluate the ternary interactions.

\section{Results and discussion}

The parameter optimization was carried out in the PARROT module of CALPHAD software Thermo-Calc [35] by minimizing the sum of squares of errors through iterations. Data collected in Table 1 were edited into an experimental data file to be used as the input. After obtaining the Gibbs energy expressions for different phases in the system, phase diagrams were calculated and plotted accordingly in the POLY module of the same software.

\subsection{Binary phase diagrams}

\subsection{1. $\mathrm{LiCl}-\mathrm{KCl}$}

Figure 1 plots the calculated phase diagram of $\mathrm{LiCl}-\mathrm{KCl}$. The eutectic point calculated occurs at 58.6 at $\% \mathrm{LiCl}$ and $626 \mathrm{~K}$. Also, due to the similarity of $\mathrm{K}$ and $\mathrm{Li}$, a small portion of $\mathrm{K}$ atoms could be substituted for $\mathrm{Li}$ atoms in $\mathrm{LiCl}$ crystal. Then $\mathrm{K}$ atoms act as the solute in the matrix of $\mathrm{LiCl}$ while $\mathrm{LiCl}$ would still keep its structure. The same rule applies to $\mathrm{KCl}$ as well. So the two solid solution phases marked as $\mathrm{LiCl}$ and $\mathrm{KCl}$ at two terminals of the phase diagram in Figure 1 are not pure $\mathrm{LiCl}$ and $\mathrm{KCl}$ but $\mathrm{LiCl}$-structure crystal and $\mathrm{KCl}$-structure crystal, respectively. Or it could be said these two solid solution phases are two different halite structure crystals.

\subsection{2. $\mathrm{LiCl}-\mathrm{PuCl}_{3}$}

$\mathrm{LiCl}-\mathrm{PuCl}_{3}$ was reported as a simple eutectic system with the eutectic point at 28 at $\% \mathrm{PuCl}_{3}$ and $734 \mathrm{~K}$ [25]. Figure 2 shows our calculated phase diagram. And the eutectic point obtained in this work is at 26.8 at\% and $731 \mathrm{~K}$, which agrees very well with experimental data 


\subsection{3. $\mathrm{KCl}-\mathrm{PuCl} \mathrm{Cl}_{3}$}

$\mathrm{KCl}-\mathrm{PuCl}_{3}$ has two intermediate components $\mathrm{K}_{2} \mathrm{PuCl}_{5}$ and $\mathrm{K}_{3} \mathrm{PuCl}_{6}$. The calculated phase is shown in Figure 3. Calculated melting point of $\mathrm{K}_{3} \mathrm{PuCl}_{6}$ is at $958 \mathrm{~K}$, compared to the value of $958 \mathrm{~K}$ reported by Benz [15]. The peritectic point calculated for $\mathrm{K}_{2} \mathrm{PuCl}_{5}$ is at 35 at $\% \mathrm{KCl}$ and $884 \mathrm{~K}$, while the values of 35 at\% $\mathrm{KCl}$ and $884 \mathrm{~K}$ reported by Benz [15] as well. Table 2 shows the optimized parameters for these binary systems and Table 4 is the comparison between the calculated results and the literature data.

\subsection{Ternary phase diagram}

There are extensive studies about the electrochemical behaviors of $\mathrm{PuCl}_{3}$ in $\mathrm{LiCl}-\mathrm{KCl}$ eutectic melt for dilution but no studies reported on the enthalpy or phase information of the LiCl-KCl$\mathrm{PuCl}_{3}$ ternary system. Here an empirical correlation derived from the surrounded-ion model, which has been employed in a $\mathrm{LiCl}-\mathrm{KCl}-\mathrm{UCl}_{3}$ system [10], was used to estimate the enthalpy of mixing of the current ternary system. On the basis of this model, the enthalpy of mixing is described by

$$
\begin{aligned}
\Delta_{\text {mix }} H & =\frac{3 x_{\mathrm{PuCl}_{3}} x_{\mathrm{LiCl}}}{1+2 x_{\mathrm{PuCl}_{3}}}\left[\frac{1}{3}\left(\frac{x_{\mathrm{LiCl}}}{1+2 x_{\mathrm{PuCl} l_{3}}}\right) \Delta \bar{H}_{\mathrm{PuCl}(\mathrm{LiCl})}^{\infty}+\left(1-\frac{x_{\mathrm{LiCl}}}{1+2 x_{\mathrm{PuCl} l_{3}}}\right) \Delta \bar{H}_{\mathrm{LiCl}\left(\mathrm{PuCl} l_{3}\right)}^{\infty}\right] \\
& +\frac{x_{\mathrm{LiCl}} x_{\mathrm{KCl}}}{1+2 x_{\mathrm{PuCl}_{3}}}\left[\frac{x_{\mathrm{KCl}}}{1+2 x_{\mathrm{PuCl}_{3}}} \Delta \bar{H}_{\mathrm{LiCl}(\mathrm{KCl})}^{\infty}+\left(1-\frac{x_{\mathrm{KCl}}}{1+2 x_{\mathrm{PuCl}_{3}}}\right) \Delta \bar{H}_{\mathrm{KCl}(\mathrm{LiCl})}^{\infty}\right] \\
& +\frac{3 x_{\mathrm{KCl}} x_{\mathrm{PuCl}_{3}}}{1+2 x_{\mathrm{PuCl}_{3}}}\left[\frac{3 x_{\mathrm{PuCl}_{3}}}{1+2 x_{\mathrm{PuCl}_{3}}} \Delta \bar{H}_{\mathrm{KCl}\left(\mathrm{PuCl}_{3}\right)}^{\infty}+\left(1-\frac{3 x_{\mathrm{PuCl}_{3}}}{1+2 x_{\mathrm{PuCl}_{3}}}\right) \frac{1}{3} \Delta \bar{H}_{\mathrm{PuCl}_{3}(\mathrm{KCl})}^{\infty}\right]
\end{aligned}
$$

where $x_{i}$ is the mole fraction of species $i$ and $\Delta \bar{H}_{i(j)}^{\infty}$ represents partial enthalpy of mixing at infinite dilution for component $i$ in the $i-j$ binary system. Figure 4 shows the calculated enthalpy of mixing for these three binary systems at $1200 \mathrm{~K}$. The similar structure of the $\mathrm{LiCl}$ and $\mathrm{KCl}$ is indicated by the pretty symmetric curve. What should attract one's attention mostly is that the minimum value of enthalpy of mixing of $\mathrm{KCl}-\mathrm{PuCl}_{3}$ system presents at $\mathrm{PuCl}_{3}$-rich side with around 0.63 mole fraction of $\mathrm{PuCl}_{3}$. This is unexpected because the only two compounds existing in the system are $\mathrm{K}_{2} \mathrm{PuCl}_{5}$ and $\mathrm{K}_{3} \mathrm{PuCl}_{6}$, which are both $\mathrm{KCl}$-rich. This phenomenon could be due to the effects of some local ordering [36,37]. But further experiments, for example, by X-ray diffraction method, are merited to investigate it and provide more insightful information. Then based on the plot of enthalpy of mixing, these $\Delta \bar{H}_{i(j)}^{\infty}$ in Eq. 13 can be obtained, which are shown in Table 5. Based the model, the enthalpy of mixing of $\mathrm{LiCl}-\mathrm{KCl}-\mathrm{PuCl}_{3}$ system at $1200 \mathrm{~K}$ 
with $x(\mathrm{LiCl}): x(\mathrm{KCl})=0.586: 0.414$ is estimated and also indicated in Figure 4, which was used as the input to extrapolate the binary systems to ternary one based on the Muggianu formalism with ternary interactions described by Eq. 5 to 9 [17].

The optimized parameters are shown in Table 2. The obtained results for A and B in Eq. 10 indicates that the enthalpy and entropy of formation are $-48155.48 \mathrm{~J} / \mathrm{mol}$ and $23.92 \mathrm{~J} / \mathrm{mol} / \mathrm{K}$, respectively, for $\mathrm{K}_{2} \mathrm{PuCl}_{5}$ crystal and $-21250.17 \mathrm{~J} / \mathrm{mol}$ and $78.80 \mathrm{~J} / \mathrm{mol} / \mathrm{K}$ for $\mathrm{K}_{3} \mathrm{PuCl}_{6}$ crystal. Based on the equilibrium information, the apparent potential of $\mathrm{PuCl}_{3}\left(E_{\mathrm{PuCl}_{3}}^{a p} \mathrm{vs}^{\mathrm{Cl}_{2} / \mathrm{Cl}^{-}}\right)$in $\mathrm{LiCl}-\mathrm{KCl}$ eutectic was calculated at a typical dilute solution with $x_{\mathrm{PuCl}_{3}}=1.25 \times 10^{-3}$ to compare with the data from the literature reviewed in 3.2. The reported values in literature and calculated results are plotted in Figure 5. The fitted correlations are listed in Table 3. As seen from the comparison, present work is in a good agreement with the literature. It demonstrates the correctness of our optimization. The maximum difference of $9 \%$ should be reasonable when considering the difference of $\mathrm{PuCl}_{3}$ mole fraction in the salt, electrode reference, and electrochemical methods used in experiments [10].

Figure 6 is the calculated isothermal section at $773 \mathrm{~K}$, which is the general temperature pyroprocessing operates at. Figure 7 shows the calculated liquidus projection. It indicates two eutectics and one quasi-peritectic. One eutectic (E1) involving $\mathrm{LiCl}, \mathrm{PuCl}_{3}$, and $\mathrm{K}_{2} \mathrm{PuCl}_{5}$ occurs at $616 \mathrm{~K}$ and another one (E2) involving $\mathrm{LiCl}, \mathrm{KCl}$, and $\mathrm{K}_{3} \mathrm{PuCl}_{6}$ at $589 \mathrm{~K}$. The quasi-peritectic involving $\mathrm{K}_{2} \mathrm{PuCl}_{5}, \mathrm{~K}_{3} \mathrm{PuCl}_{6}$, and $\mathrm{LiCl}$ appears at $658 \mathrm{~K}$. There is also a monovariant eutectic involving $\mathrm{LiCl}$ and $\mathrm{K}_{2} \mathrm{PuCl}_{5}$ at $690 \mathrm{~K}$. All these phase reactions have been presented in Table 4 .

Three temperatures of 723,773 , and $823 \mathrm{~K}$ are taken to be analyzed in detail. Figure 8 shows the calculated liquidus projection of these three temperatures. The dashed line stands for the compositions with $x(\mathrm{LiCl}): x(\mathrm{KCl})=0.586: 0.414$. The squares represent where solid first appears and the circles represent where $\mathrm{PuCl}_{3}$ starts to become solid, which should be the limit of solubility of $\mathrm{PuCl}_{3}$ in $\mathrm{LiCl}-\mathrm{KCl}$ eutectic salt at different temperatures. The mole fractions of $\mathrm{PuCl}_{3}$ at these positions are list in Table 6. Generally, the solubility $S_{\mathrm{PuCl}_{3}}$ in the unit of mole fraction can be expressed by [38]

$$
\log S_{P_{u C l}}=a+\frac{b}{T}
$$

which is used to fit the calculated data in Table 6. Figure 9 shows the fitting result, which gives the correlation of 


$$
\log S_{P_{u C l_{3}}}=0.2415-\frac{478.37}{T}
$$

Figure 10 shows the Gibbs energy of formation of $\mathrm{PuCl}_{3}$ in $\mathrm{LiCl}-\mathrm{KCl}$ eutectic up to 5 at\% at different temperatures. The Gibbs energy change at 4.3 at $\% \mathrm{PuCl}_{3}$ at $723 \mathrm{~K}$ is due to the precipitation of $\mathrm{LiCl}$ in the liquid. It shows that the Gibbs energy is dependent on the concentration and increases with it, which should be noted but is not well reported in the literature.

\section{Conclusions}

Thermodynamic assessment for the $\mathrm{LiCl}-\mathrm{KCl}-\mathrm{PuCl}_{3}$ ternary system has been carried out by CALPHAD method using two-sublattice model. Binary systems of $\mathrm{LiCl}-\mathrm{KCl}, \mathrm{LiCl}-\mathrm{PuCl}_{3}$, and $\mathrm{KCl}-\mathrm{PuCl}_{3}$ are primarily evaluated based on available phase information and enthalpy of mixing. The calculation shows consistency with experimental data. The enthalpy of mixing of LiCl-KCl$\mathrm{PuCl}_{3}$ was estimated by an empirical correlation for the asymmetric ionic salt system. The estimation combined with the output from binary systems and previous electrochemical studies were used as the input to extrapolate to ternary system.

The solubility and Gibbs energy of formation of $\mathrm{PuCl}_{3}$ in $\mathrm{LiCl}-\mathrm{KCl}$ eutectic were obtained from the optimized results. Other interesting thermodynamic properties could be derived from it as well. This study will help to evaluate the salt status and $\mathrm{PuCl}_{3}$ properties during pyroprocessing and will also contribute to evaluating other salt systems with more components. Also, the properties of $\mathrm{PuCl}_{3}$ with a full range of composition may benefit the safeguards of pyroprocessing of detecting the concentration of $\mathrm{PuCl}_{3}$ in the electrorefining batch.

\section{Acknowledgements}

This research has been performed using funding received from the DOE Office of Nuclear Energy's Nuclear Energy University Programs (Project 13-4908). Also, the authors would like to thank Jeremy Isler in Ohio State University for the useful comments. 


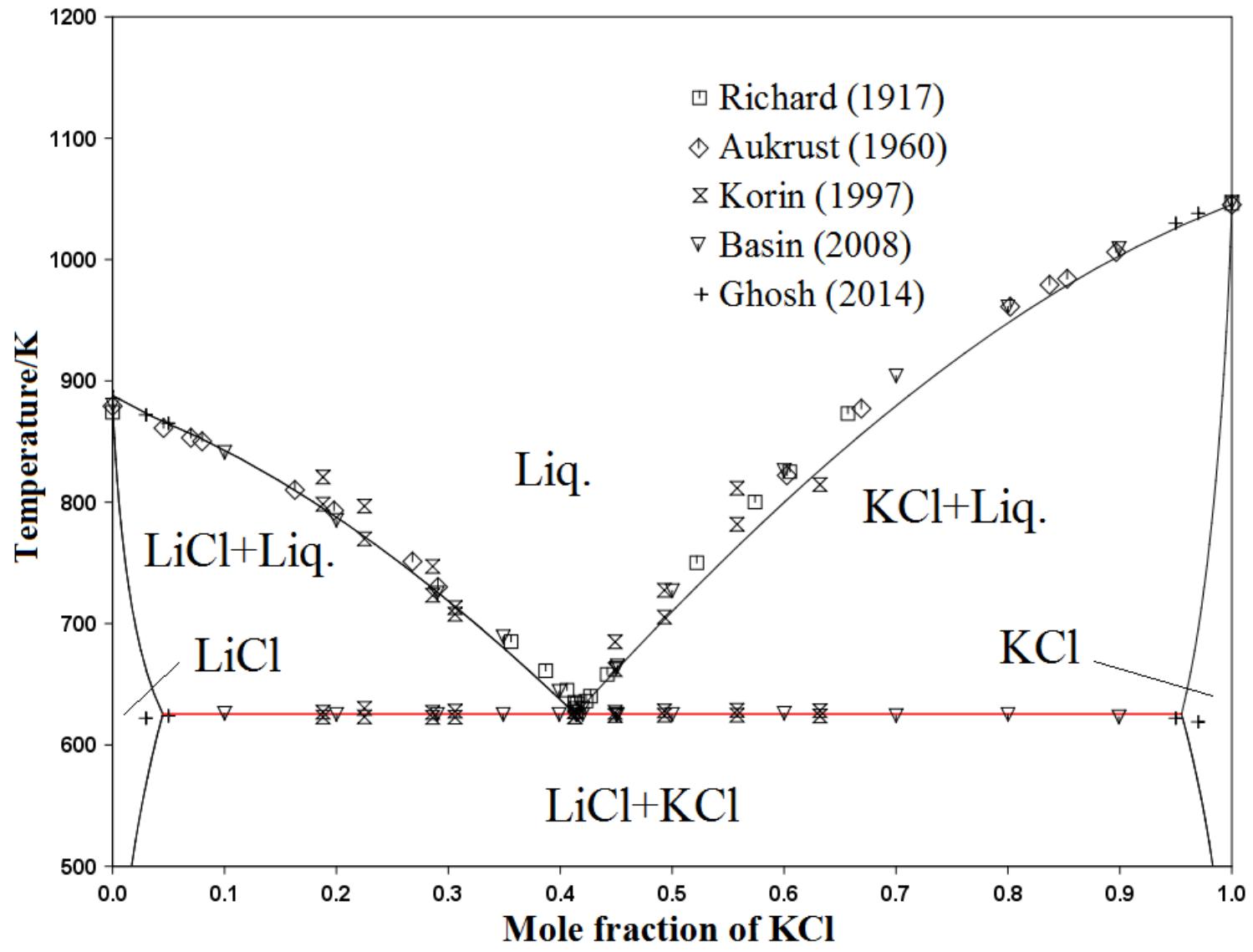

Figure 1. Calculated $\mathrm{LiCl}-\mathrm{KCl}$ phase diagram (solid lines) 


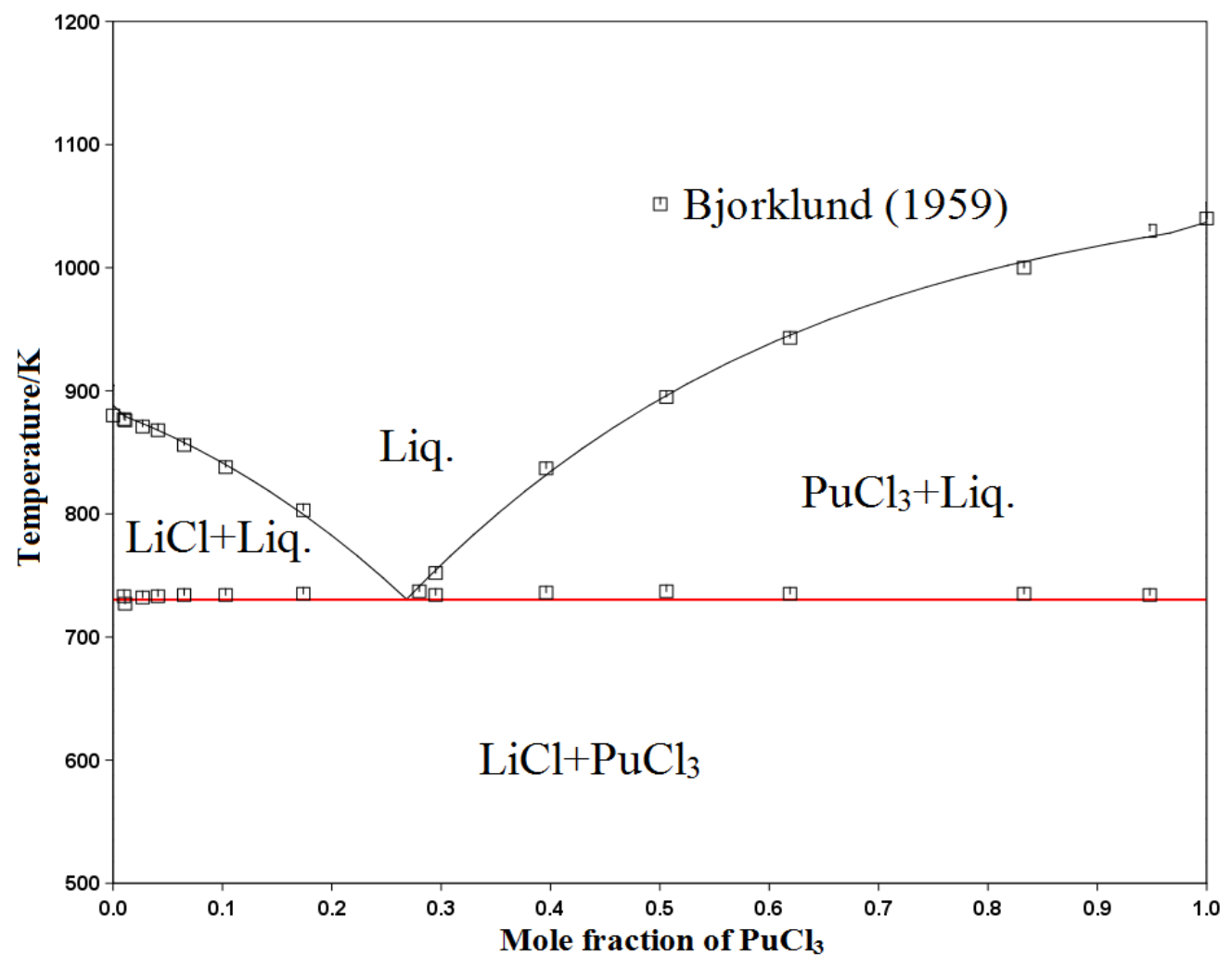

Figure 2. Calculated $\mathrm{LiCl}-\mathrm{PuCl}_{3}$ phase diagram (solid lines) 


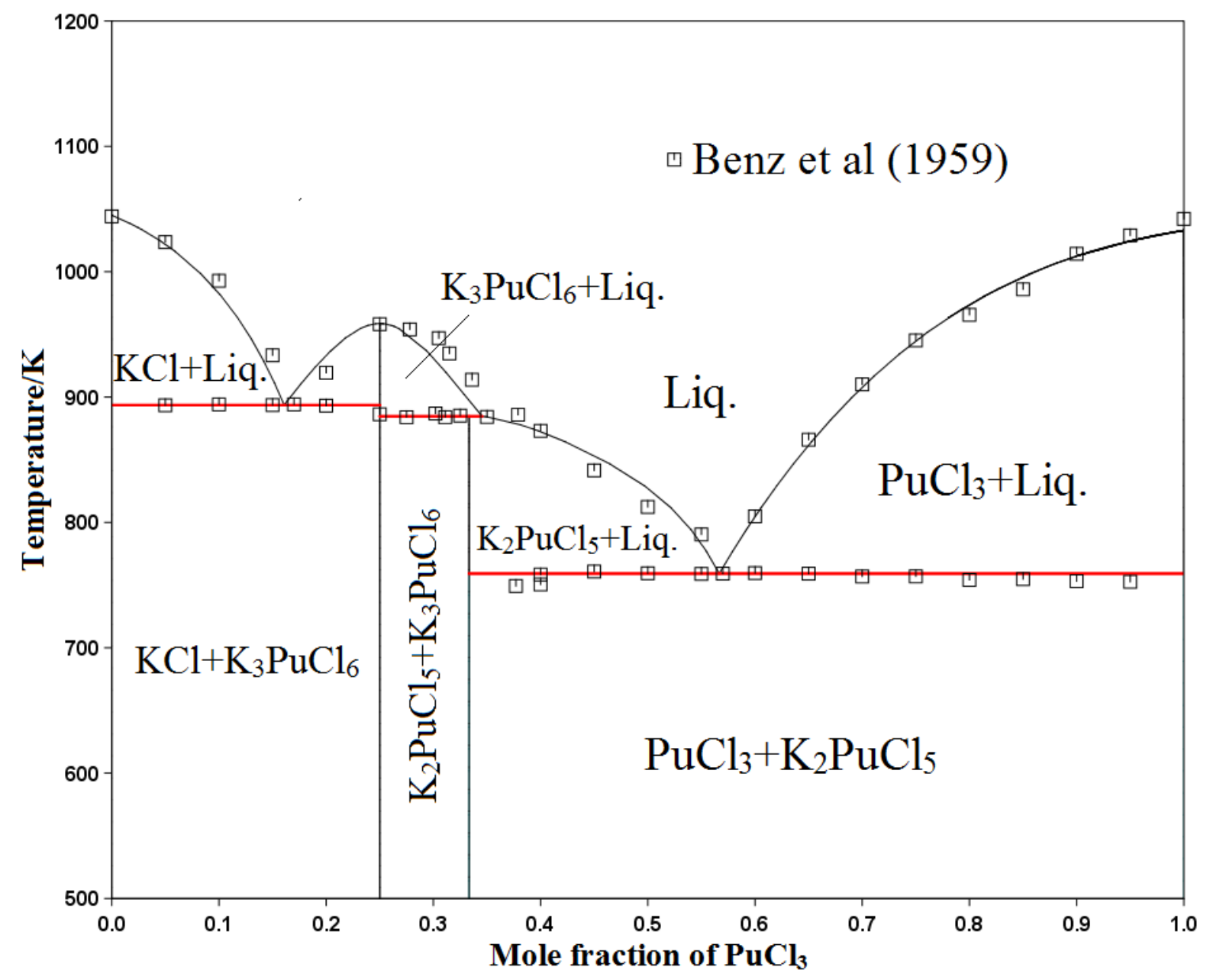

Figure 3. Calculated $\mathrm{KCl}-\mathrm{PuCl}_{3}$ phase diagram (solid lines) 


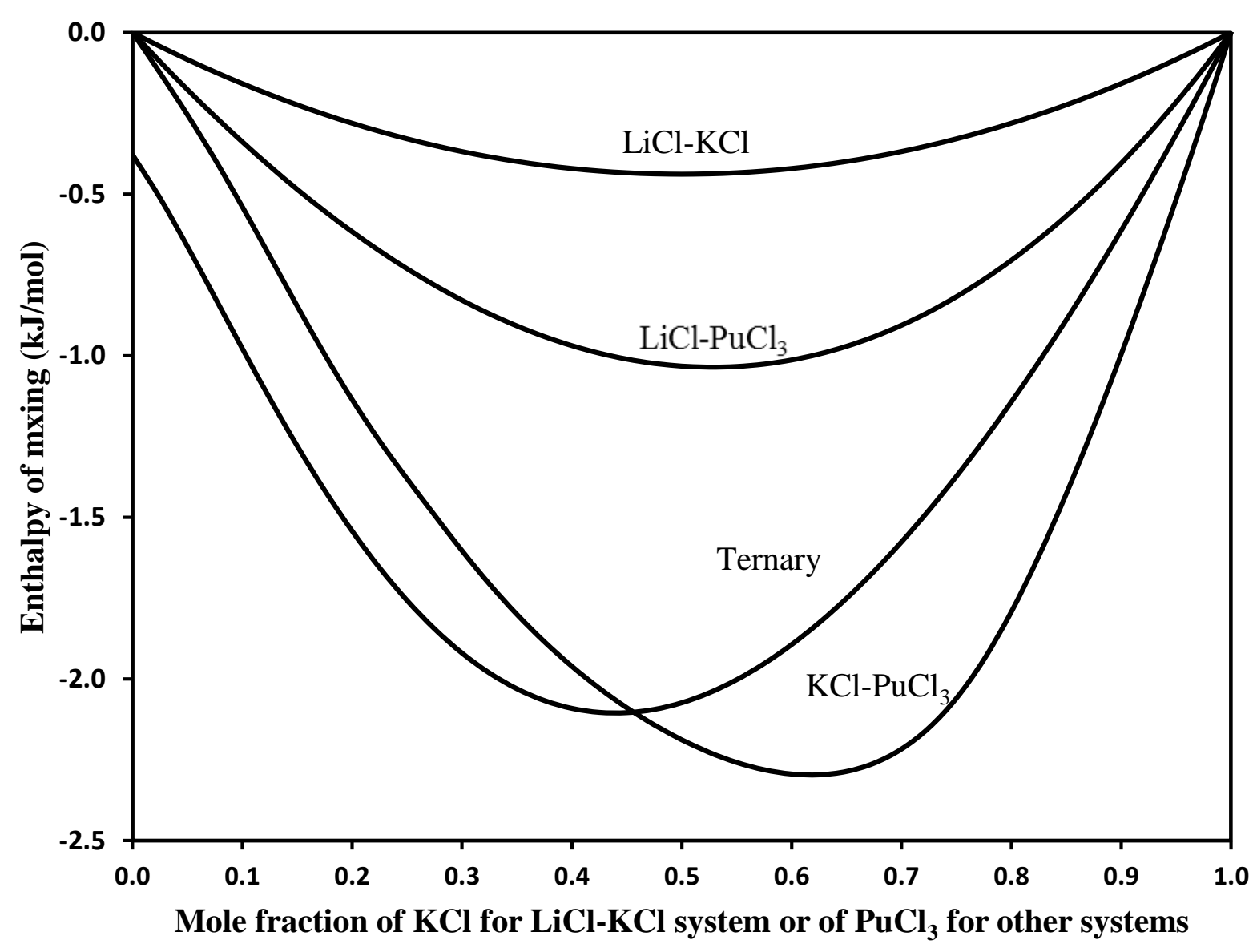

Figure 4. Calculated enthalpy of mixing for $\mathrm{LiCl}-\mathrm{KCl}, \mathrm{LiCl}-\mathrm{PuCl}_{3}, \mathrm{KCl}-\mathrm{PuCl}_{3}$, and $\mathrm{LiCl}-\mathrm{KCl}-$ $\mathrm{PuCl}_{3}$ ternary system with $x(\mathrm{LiCl}): x(\mathrm{KCl})=0.586: 0.414$ at $1200 \mathrm{~K}$ 


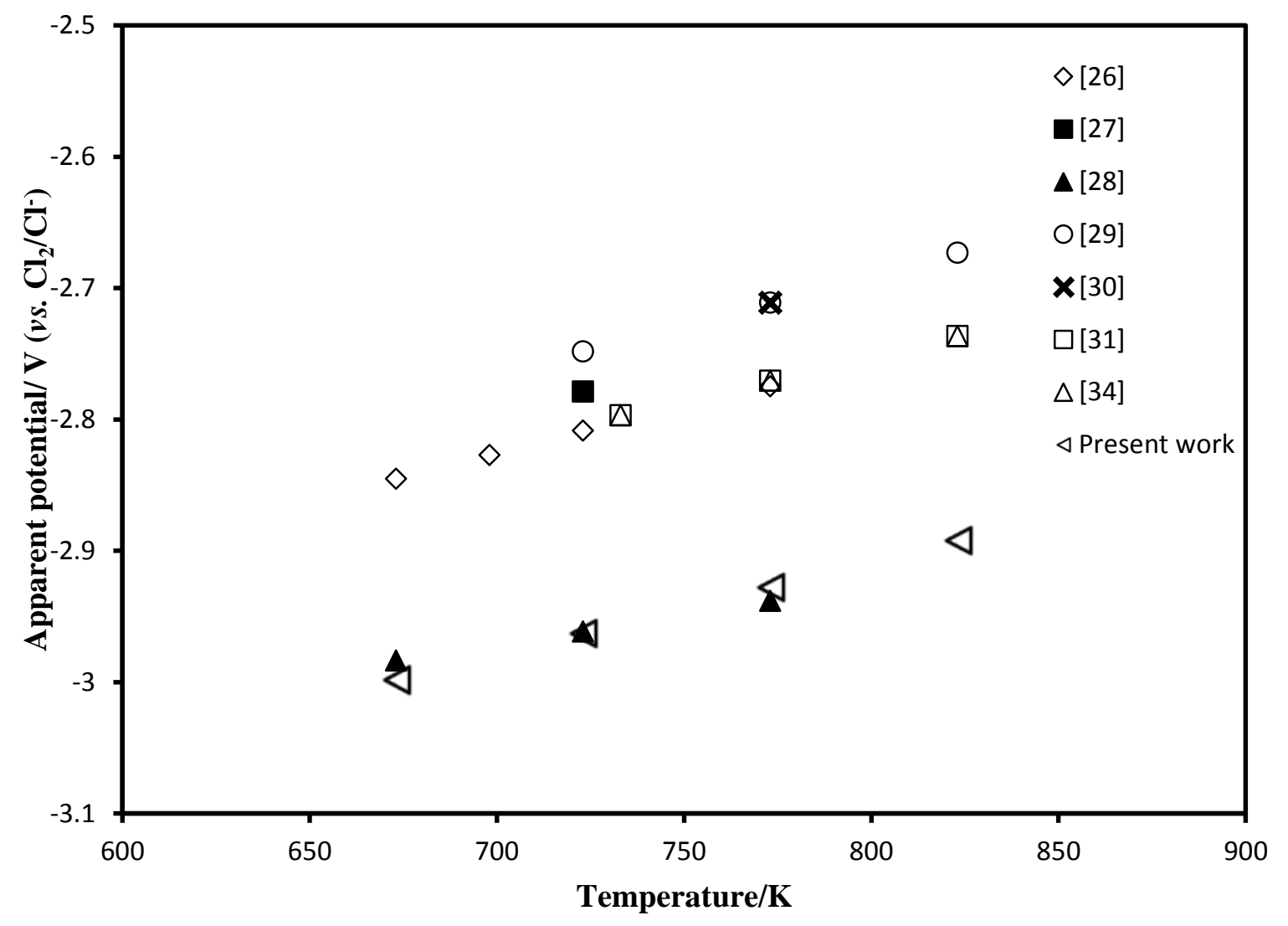

Figure 5. Comparison of apparent potential for $\mathrm{PuCl}_{3}$ in $\mathrm{LiCl}-\mathrm{KCl}$ eutectic 


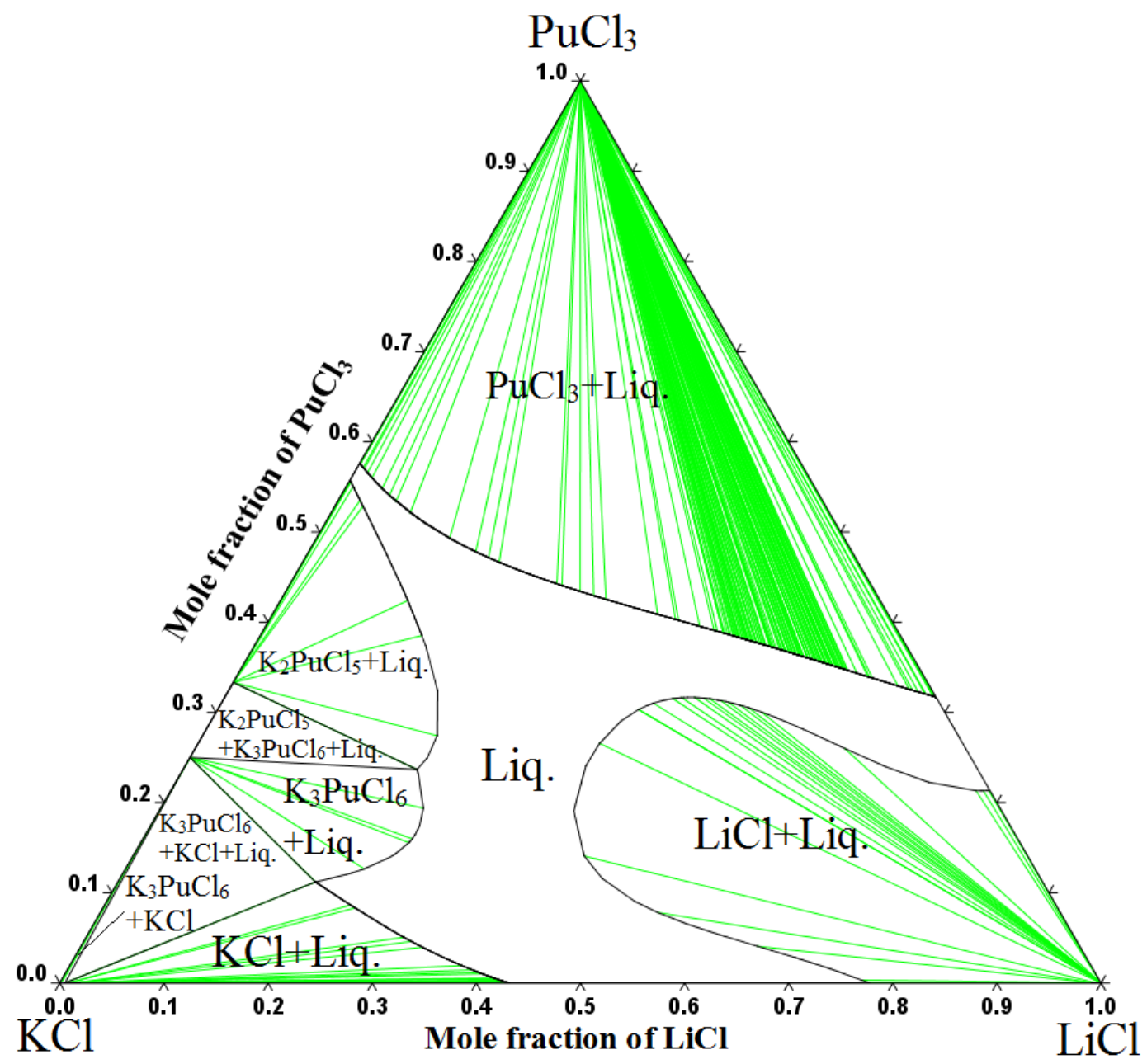

Figure 6. Calculated isothermal section of $\mathrm{LiCl}-\mathrm{KCl}-\mathrm{PuCl}_{3}$ at $773 \mathrm{~K}$ 


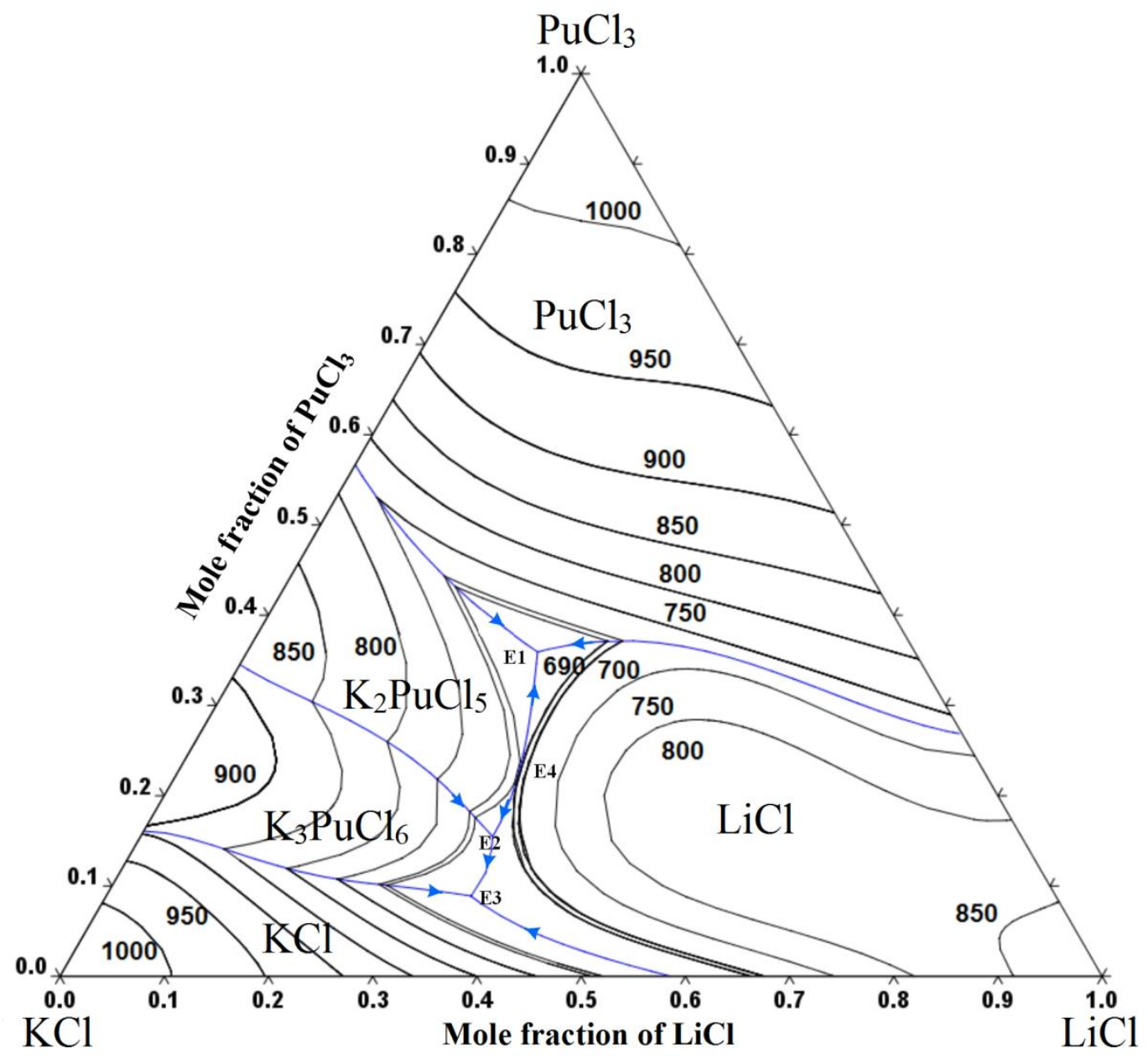

Figure 7. Calculated liquidus projection for $\mathrm{LiCl}-\mathrm{KCl}-\mathrm{PuCl}_{3}$ system 


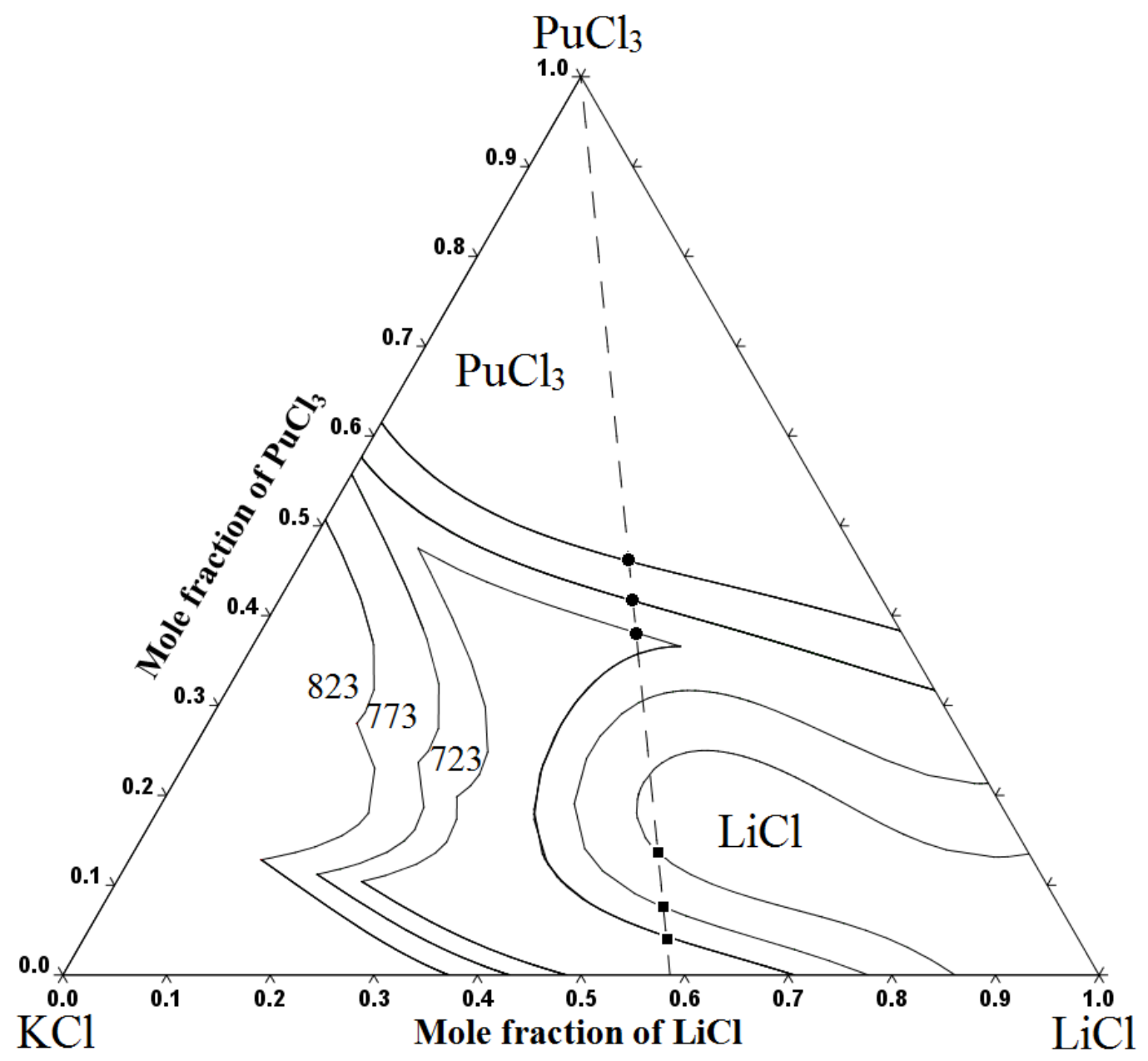

Figure 8. Calculated liquidus projection for $\mathrm{LiCl}-\mathrm{KCl}-\mathrm{PuCl}_{3}$ system at 723,773 , and $823 \mathrm{~K}$ 


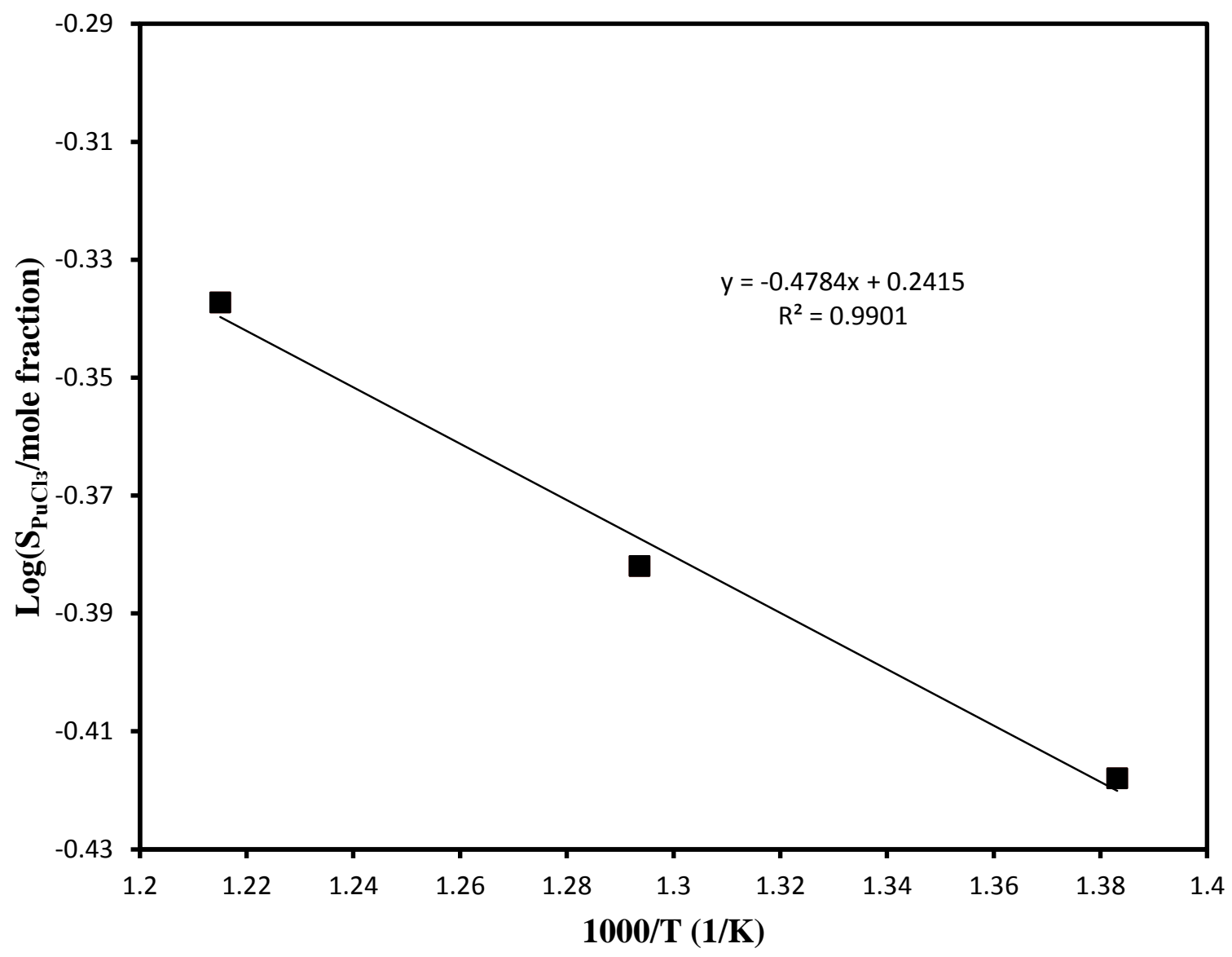

Figure 9. Calculated solubility of $\mathrm{PuCl}_{3}$ in $\mathrm{LiCl}-\mathrm{KCl}$ eutectic and the fitting curve 


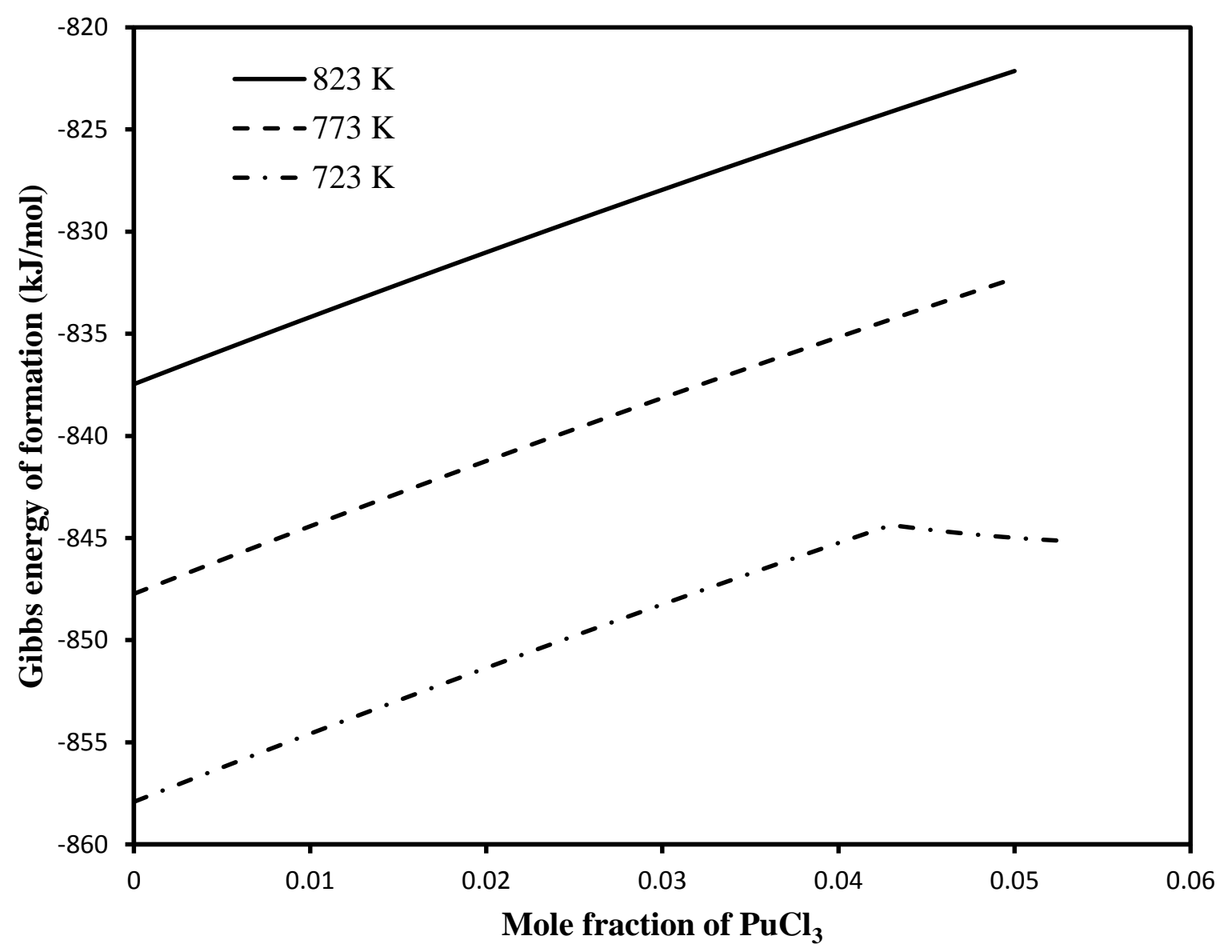

Figure 10. Calculated Gibbs energy of formation of $\mathrm{PuCl}_{3}$ in $\mathrm{LiCl}-\mathrm{KCl}$ eutectic at 723, 773, and $823 \mathrm{~K}$ 
Table 1. Gibbs energy database input for the $\mathrm{LiCl}-\mathrm{KCl}-\mathrm{PuCl}_{3}$ system

\begin{tabular}{|c|c|c|c|}
\hline \multicolumn{2}{|c|}{ Parameters } & \multirow{2}{*}{$\begin{array}{c}\text { Functions } \\
=-395043.11-16.124629 T-4.0793198 T \ln (T)-0.071486773 T^{2}\end{array}$} & \multirow{2}{*}{$\frac{\text { Reference }}{[10]}$} \\
\hline Liquid & ${ }^{0} G_{L i: C l}^{L i q .}$ & & \\
\hline & & $+1.4175712 \times 10^{-5} T^{3}-394814 T^{-1}, 298.15 \mathrm{~K}<T<883 \mathrm{~K}$ & \\
\hline & & $=-417132.497+421.76137 T-73.3062 T \ln (T)$ & \\
\hline & & $+0.004715055 T^{2}-16535 T^{-1}, 883 \mathrm{~K}<T<2000 \mathrm{~K}$ & \\
\hline & ${ }^{0} G_{K: C l}^{L i q .}$ & $-427035.9+247.546026 T-52.801 T \ln (T)+0.93665 \times 10^{-3} T^{2}$ & [10] \\
\hline & & $-2.409027 \times 10^{-6} T^{3}+97730 T^{-1}, 298.15 \mathrm{~K}<T<750 \mathrm{~K}$ & \\
\hline & & $-648588.535+3031.321656 T-469.507 T \ln (T)+350.0937 \times 10^{-3} T^{2}$ & \\
\hline & & $-57.429763 \times 10^{-6} T^{3}+22222816 T^{-1}, 750 \mathrm{~K}<T<1045 \mathrm{~K}$ & \\
\hline & & $-443361.737+404.765951 T-73.3994 T \ln (T), 1045 \mathrm{~K}<T<2000 \mathrm{~K}$ & \\
\hline & ${ }^{0} G_{P u: C l}^{L L q}$ & $-1037967.35+479.21511 T-94.12701 T \ln (T)-0.0135962 T^{2}$ & [39] \\
\hline & & $-6.25 \times 10^{-10} T^{3}-28380 T^{-1}+63579-61.5653437 T$ & \\
\hline & & $298.15 \mathrm{~K}<T<1033 \mathrm{~K}$ & \\
\hline & & $-1064596.34+766.881722 T-133.888 T \ln (T)+63597$ & \\
\hline & & $-61.5653437 T, 1033 \mathrm{~K}<T<1500 \mathrm{~K}$ & \\
\hline & ${ }^{0} G_{K_{3}}^{\text {Liqu}} \mathrm{Cl}_{6}$ & $3{ }^{0} G_{K C l}^{L i q .}+{ }^{0} G_{P u C l_{3}}^{L i q .}-6700-66.7 T$ & [40] \\
\hline \multirow[t]{16}{*}{ Solid } & ${ }^{0} G_{L i: C l}^{S}$ & $=423060.237+246.636632 T-44.7048 T \ln (T)-0.0089638 T^{2}$ & [10] \\
\hline & & $-3.1058 \times 10^{-7} T^{3}+97229 T^{-1}, 289.15 \mathrm{~K}<T<883 \mathrm{~K}$ & \\
\hline & & $=490131.802+821.73726 T-124.44483 T \ln (T)+0.025420461 T^{2}$ & \\
\hline & & $-1.523016 \times 10^{-6} T^{3}+9722242 T^{-1}, 883 \mathrm{~K}<T<2000 \mathrm{~K}$ & \\
\hline & ${ }^{0} G_{K: C l}^{S}$ & $-452489.937+263.149637 T-51.2948 T \ln (T)-1.40523 \times 10^{-3}$ & [10] \\
\hline & & $-1731001 \times 10^{-6} T^{3}+76732 T^{-1}, 298.15 \mathrm{~K}<T<700 \mathrm{~K}$ & \\
\hline & & $-487176.143+762.308381 T-127.7773 T \ln (T)$ & \\
\hline & & $+72.96818 \times 10^{-3} T^{2}-15.190909 \times 10^{-6} T^{3}+3002008 T^{-1}$ & \\
\hline & & $700 \mathrm{~K}<T<800 \mathrm{~K}$ & \\
\hline & & $-729641.417+3635.724945 T-553.3953 T \ln (T)$ & \\
\hline & & $+406.611005 \times 10^{-3} T^{2}-63.587069 \times 10^{-6} T^{3}$ & \\
\hline & & $+28867854 T^{-1}, 800 \mathrm{~K}<T<1045 \mathrm{~K}$ & \\
\hline & & $-9292757.859+83732.64789 T-11945.8623451 T \ln (T)$ & \\
\hline & & $+7098.951923 \times 10^{-3} T^{2}-795.735427 \times 10^{-6} T^{3}$ & \\
\hline & & $+1229243789 T^{-1}, 1045 \mathrm{~K}<T<1100 \mathrm{~K}$ & \\
\hline & & $-469544.033+429.820456-73.3994 T \ln (T), 1100 \mathrm{~K}<T<2000 \mathrm{~K}$ & \\
\hline
\end{tabular}




\begin{tabular}{lll}
\hline${ }^{0} G_{P u C l_{3}}^{S}$ & $-1.37967 .35+479.21511 T-94.12701 T \ln (T)-0.0135862 T^{2}$ \\
& $-6.25 \times 10^{-10} T^{3}-28380 T^{-1}, 298.15 \mathrm{~K}<T<1033 \mathrm{~K}$ \\
& $-1064596.34+766.881722 T-133.888 T \ln (T), 1033 \mathrm{~K}<T<1500 \mathrm{~K}$ \\
\hline
\end{tabular}

Table 2. Optimized parameters for the $\mathrm{LiCl}-\mathrm{KCl}-\mathrm{PuCl}_{3}$ system

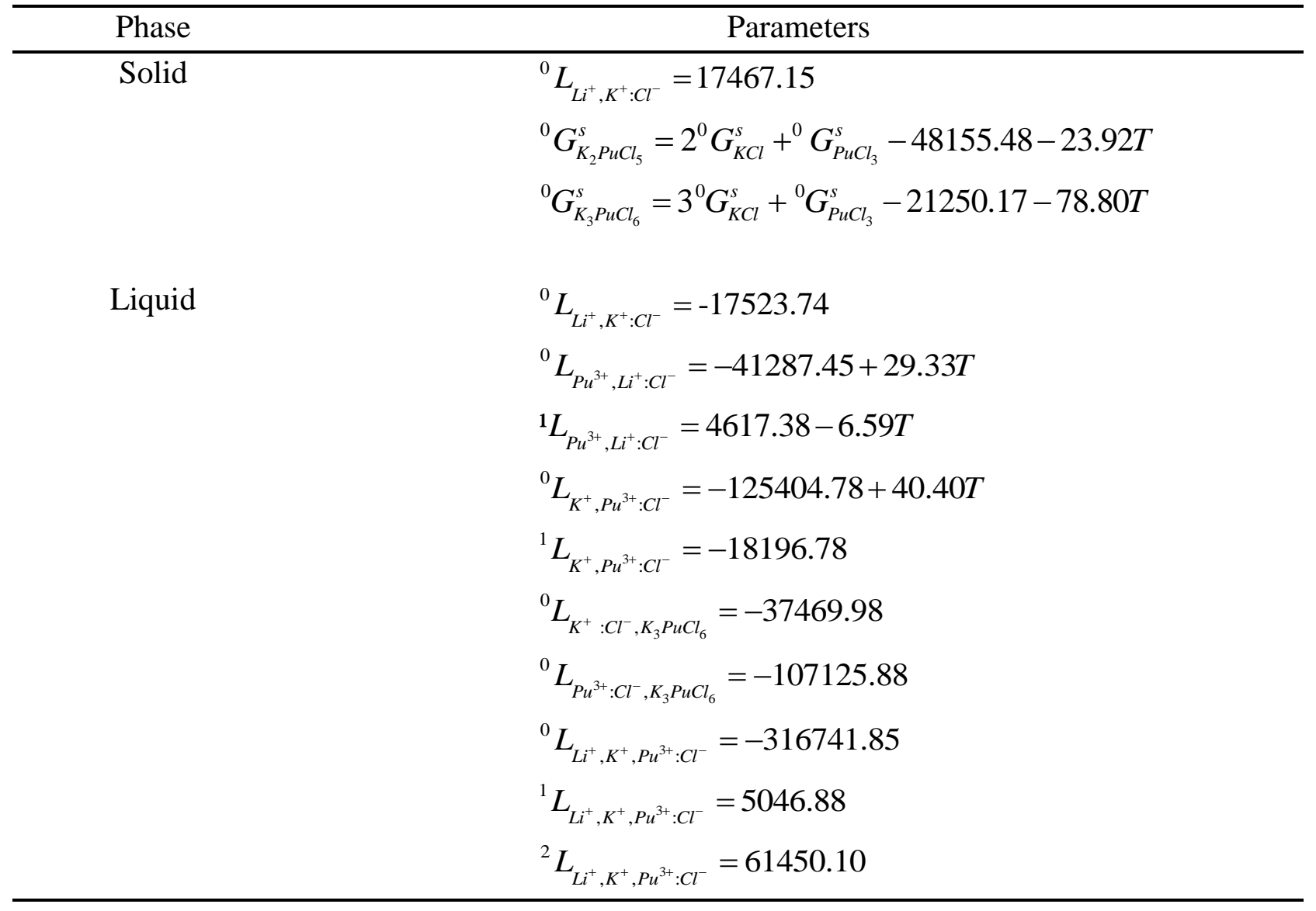


Table 3. Comparison of apparent potential for $\mathrm{PuCl}_{3}$ in $\mathrm{LiCl}-\mathrm{KCl}$ eutectic

\begin{tabular}{lcc}
\hline Apparent potential/ $/ \mathrm{V} v s . \mathrm{Cl}_{2} / \mathrm{Cl}^{-}$ & Temperature/K & Reference \\
\hline$E_{P u C_{3}}^{a p}=-3.3187+7.044 \times 10^{-4} T$ & $673-773$ & {$[26]$} \\
$E_{P u C_{3}}^{a p}=-3.2950+6.594 \times 10^{-4} T$ & $673-773$ & {$[28]$} \\
$E_{P u C_{3}}^{a p}=-3.2904+7.500 \times 10^{-4} T$ & $723-823$ & {$[29]$} \\
$E_{P u C_{3}}^{a p}=-3.2980+7.600 \times 10^{-4} T$ & $723-823$ & {$[30]$} \\
$E_{P u C_{3}}^{a p}=-3.3048+6.910 \times 10^{-4} T$ & $733-823$ & {$[31]$} \\
$E_{P u C_{3}}^{a p}=-3.3048+6.910 \times 10^{-4} T$ & $733-823$ & {$[34]$} \\
$E_{P u C_{3}}^{a p}=-3.4727+7.058 \times 10^{-4} T$ & $673-823$ & Present work \\
\hline
\end{tabular}

Table 4. Phase reactions in $\mathrm{LiCl}-\mathrm{KCl}-\mathrm{PuCl}_{3}$ system

\begin{tabular}{|c|c|c|c|c|c|}
\hline \multirow[t]{2}{*}{ Phase reaction } & \multirow{2}{*}{$\begin{array}{l}\text { Reaction } \\
\text { type }\end{array}$} & \multicolumn{2}{|c|}{ Composition of liquid } & \multirow[t]{2}{*}{$\mathrm{T} / \mathrm{K}$} & \multirow[t]{2}{*}{ Reference } \\
\hline & & $x_{\mathrm{LiCl}}$ & $x_{\mathrm{PuCl}_{3}}$ & & \\
\hline \multicolumn{6}{|l|}{ Binary } \\
\hline \multirow[t]{2}{*}{ Liquid $\rightleftharpoons \mathrm{LiCl}+\mathrm{KCl}$} & Eutectic & 0.586 & - & 626 & This work \\
\hline & & $0.585 \pm 0.003$ & - & $628 \pm 3$ & {$[10,20-23]$} \\
\hline \multirow[t]{2}{*}{ Liquid $\rightleftharpoons \mathrm{LiCl}+\mathrm{PuCl}_{3}$} & Eutectic & - & 0.268 & 731 & This work \\
\hline & & - & 0.28 & 734 & \\
\hline \multirow[t]{2}{*}{ Liquid $\rightleftharpoons \mathrm{KCl}+\mathrm{K}_{3} \mathrm{PuCl}_{6}$} & Eutectic & - & 0.161 & 895 & This work \\
\hline & & - & 0.17 & 894 & [15] \\
\hline \multirow[t]{2}{*}{ Liquid $\rightleftharpoons \mathrm{K}_{3} \mathrm{PuCl}_{6}$} & Congruent & - & 0.250 & 958 & This work \\
\hline & Peritectic & - & $\begin{array}{l}0.250 \\
0.350\end{array}$ & $\begin{array}{l}958 \\
884\end{array}$ & $\begin{array}{l}{[15]} \\
\text { This work }\end{array}$ \\
\hline Liquid $+\mathrm{K}_{3} \mathrm{PuCl}_{6} \rightleftharpoons \mathrm{K}_{2} \mathrm{PuCl}_{5}$ & & - & 0.35 & 884 & [15] \\
\hline \multirow[t]{2}{*}{ Liquid $\rightleftharpoons \mathrm{PuCl}_{3}+\mathrm{K}_{2} \mathrm{PuCl}_{5}$} & Eutectic & - & 0.564 & 759 & This work \\
\hline & & - & 0.57 & 759 & [15] \\
\hline \multicolumn{6}{|l|}{ Ternary } \\
\hline \multirow{2}{*}{$\begin{array}{l}\text { Liquid } \rightleftharpoons \mathrm{LiCl}+\mathrm{KCl}+\mathrm{K}_{3} \mathrm{PuCl}_{6} \\
\text { Liquid }+\mathrm{K}_{2} \mathrm{PuCl}_{5} \rightleftharpoons \mathrm{K}_{3} \mathrm{PuCl}_{6}+\mathrm{LiCl}\end{array}$} & Eutectic & 0.350 & 0.089 & 589 & This work \\
\hline & Quasi-peritectic & 0.338 & 0.155 & 658 & This work \\
\hline \multirow{2}{*}{$\begin{array}{l}\text { Liquid } \rightleftharpoons \mathrm{LiCl}+\mathrm{PuCl}_{3}+\mathrm{K}_{2} \mathrm{PuCl}_{5} \\
\text { Liquid } \rightleftharpoons \mathrm{LiCl}+\mathrm{K}_{2} \mathrm{PuCl}_{5}\end{array}$} & Eutectic & 0.279 & 0.359 & 616 & This work \\
\hline & Eutectic & 0.324 & 0.225 & 690 & This work \\
\hline
\end{tabular}

Table 5. Partial enthalpies at infinite dilution at $1200 \mathrm{~K}$

\begin{tabular}{llll}
\hline$i$ & $j$ & $\Delta \bar{H}_{i(j)}^{\infty}(\mathrm{kJ} / \mathrm{mol})$ & $\Delta \bar{H}_{j(i)}^{\infty}(\mathrm{kJ} / \mathrm{mol})$ \\
\hline $\mathrm{LiCl}$ & $\mathrm{KCl}$ & -15.33 & -15.77 \\
$\mathrm{LiCl}$ & $\mathrm{PuCl}_{3}$ & -40.48 & -33.84 \\
\hline
\end{tabular}




\begin{tabular}{llll}
\hline $\mathrm{KCl}$ & $\mathrm{PuCl}_{3}$ & -99.66 & -53.86 \\
\hline
\end{tabular}

Table 6. Mole fraction of $\mathrm{PuCl}_{3}$ at the squares and circles in Figure 8

\begin{tabular}{llll}
\hline & $723 \mathrm{~K}$ & $773 \mathrm{~K}$ & $823 \mathrm{~K}$ \\
\hline Squares & 0.043 & 0.076 & 0.137 \\
Circles & 0.382 & 0.415 & 0.460 \\
\hline
\end{tabular}




\section{References}

[1] M. Misra, K.S. Raja, A.V. Jaques, and S. Baral. "Effect of Addition of Multi-Component Lanthanides to $\mathrm{LiCl}-\mathrm{KCl}$ Eutectic on Thermal and Electrochemical Properties." ECS Transactions33.7 (2010): 351-360.

[2] M. Li, Q. Gu, W. Han, X. Zhang, Y. Sun, M. Zhang and Y. Yan. "Electrochemical behavior of $\mathrm{La}$ (III) on liquid $\mathrm{Bi}$ electrode in $\mathrm{LiCl}-\mathrm{KCl}$ melts.-Determination of thermodynamic properties of La-Bi and Li-Bi intermetallic compounds." RSC Advances (2015).

[3 ] Y. Wang, M. Li, W. Han, M. Zhang, Y. Yang, Y. Sun, Y. Zhao and Y. Yan. "Electrochemical extraction and separation of praseodymium and erbium on reactive magnesium electrode in molten salts."Journal of Solid State Electrochemistry (2015): 1-10.

[4] T. Koyama, M. Iizuka, Y. Shoji, R. Fujita, H. Tanaka, T. Kobayashi and M. Tokiwai. "An experimental study of molten salt electrorefining of uranium using solid iron cathode and liquid cadmium cathode for development of pyrometallurgical reprocessing." Journal of nuclear science and technology 34.4 (1997): 384-393.

[5] W. Zhou and J. Zhang. "Direct Calculation of Concentration-Dependent Activity Coefficient of UCl3 in Molten LiCl-KCl." Journal of The Electrochemical Society 162.10 (2015): E199E204.

[6] W. Zhou and J. Zhang. "Chemical diffusion coefficient calculation of U3+ in LiCl-KCl molten salt." Progress in Nuclear Energy 91 (2016): 170-174.

[7] Y. Wang, W. Zhou and J. Zhang. "Investigation of concentration-dependence of thermodynamic properties of lanthanum, yttrium, scandium and terbium in eutectic $\mathrm{LiCl}-\mathrm{KCl}$ molten salt." Journal of Nuclear Materials 478 (2016): 61-73.

[8] M. He, G. Lu, Z. Kang and Y. Zhang. "Thermodynamic assessment of the $\mathrm{LiCl}-\mathrm{KCl}-\mathrm{CeCl} 3$ system." Calphad 49 (2015): 1-7.

[9] T. Shujian, L. Qingfan, L. Shixiang and Z. Chaogui. "Phase diagram of the ternary system CeCl 3-KCl-LiCl."Journal of alloys and compounds 274.1 (1998): 142-147.

[10] S. Ghosh, B.P. Reddy, K. Nagarajan and K.H. Kumar. "Experimental investigations and thermodynamic modelling of KCl-LiCl-UCl 3 system." Calphad 45 (2014): 11-26.

[11] H.L. Lukas, S.G. Fries and B. Sundman. Computational thermodynamics: the Calphad method. Vol. 131. Cambridge: Cambridge university press, 2007.

[ 12 ] U.R. Kattner. "The thermodynamic modeling of multicomponent phase equilibria." JOM 49.12 (1997): 14-19.

[13] M. Hillert, B. Jansson, B. Sundman. "A two-sublattice model for molten solutions with different tendency for ionization." Metallurgical Transactions A 16.1 (1985): 261-266.

[14] B. Sundman. "Modification of the two-sublattice model for liquids." Calphad15.2 (1991): $109-119$.

[15] R. Benz, M. Kahn and J.A. Leary. "Phase Equilibria of the Binary System PuCl3KCl." The Journal of Physical Chemistry 63.11 (1959): 1983-1984. 
[16] V.Y. Buz'ko, G.Y. Chuiko and K.B. Kushkhov. "DFT study of the structure and stability of $\mathrm{Pu}$ (III) and Pu (IV) chloro complexes." Russian Journal of Inorganic Chemistry 57.1 (2012): 62-67.

[17] Y. M. Muggianu, M. Gambino, J. P. Bros, Enthalpies of formation of liquid alloys, J. Chim. Phys., 72 (1975): 83-88

[18] O. Redlich and A.T. Kister. "Algebraic representation of thermodynamic properties and the classification of solutions." Industrial \& Engineering Chemistry 40.2 (1948): 345-348.

[19] H. Kopp. "Investigations of the specific heat of solid bodies."Philosophical Transactions of the Royal Society of London (1865): 71-202.

[20] T.W. Richards and W.B. Meldrum. "THE MELTING POINTS OF THE CHLORIDES OF LITHIUM, RUBIDIUM AND CAESIUM, AND THE FREEZING POINTS OF BINARY AND TERNARY MIXTURES OF THESE SALTS, INCLUDING ALSO POTASSIUM AND SODIUM CHLORIDE." Journal of the American Chemical Society 39.9 (1917): 1816-1828.

[21] E. Aukrust, B. Björge, H. Flood and T. Førland. "ACTIVITIES IN MOLTEN SALT MIXTURES OF POTASSIUM-LITHIUM-HALIDE MIXTURES: A PRELIMINARY REPORT."Annals of the New York Academy of Sciences 79.11 (1960): 830-837.

[22] E. Korin and L. Soifer. "Thermal analysis of the system KCl-LiCl by differential scanning calorimetry." Journal of thermal analysis 50.3 (1997): 347-354.

[23] A.S. Basin, A.B. Kaplun, A.B. Meshalkin and N.F. Uvarov. "The LiCl-KCl binary system." Russian Journal of Inorganic Chemistry 53.9 (2008): 1509-1511.

[24] L.S. Hersh and O.J. Kleppa. "Enthalpies of mixing in some binary liquid halide mixtures." The Journal of Chemical Physics 42.4 (1965): 1309-1322.

[25] C.W. Bjorklund, J.G. Reavis, J.A. Leary and K.A. Walsh. "Phase Equilibria in the Binary Systems PuCl3-NaCl and PuCl3-LiCl." The Journal of Physical Chemistry 63.10 (1959): 17741777.

[26] J.J. Roy, L.F. Grantham, D.L. Grimmett, S.P. Fusselman, C.L. Krueger, T.S. Storvick, T. Inoue, Y. Sakamura and N. Takahashi. "Thermodynamic Properties of $\mathrm{U}, \mathrm{Np}, \mathrm{Pu}$, and $\mathrm{Am}$ in Molten LiCl-KCl Eutectic and Liquid Cadmium." Journal of the Electrochemical Society 143.8 (1996): 2487-2492.

[27] Y. Sakamura, T. Hijikata, K. Kinoshita, T. Inoue, T.S. Storvick, C.L. Krueger, J.J. Roy, D.L. Grimmett, S.P. Fusselman and R.L. Gay. "Measurement of standard potentials of actinides (U, $\mathrm{Np}, \mathrm{Pu}, \mathrm{Am})$ in $\mathrm{LiCl}-\mathrm{KCl}$ eutectic salt and separation of actinides from rare earths by electrorefining." Journal of alloys and compounds 271 (1998): 592-596.

[28] Y. Sakamura, O. Shirai, T. Iwai and Y. Suzuki. "Distribution behavior of plutonium and americium in LiCl-KCl eutectic/liquid cadmium systems." Journal of Alloys and Compounds 321.1 (2001): 76-83.

[29] O. Shirai, M. IIZUKA, T. IWAI and Y. ARAI. "Electrode reaction of Pu3+/Pu couple in $\mathrm{LiCl}-\mathrm{KCl}$ eutectic melts: comparison of the electrode reaction at the surface of liquid $\mathrm{Bi}$ with that at a solid Mo electrode." Analytical sciences 17.1 (2001): 51-57. 
[30] O. Shirai, H. Yamana and Y. Arai. "Electrochemical behavior of actinides and actinide nitrides in LiCl-KCl eutectic melts." Journal of alloys and compounds 408 (2006): 1267-1273.

[31] J. Serp, R.J.M. Konings, R. Malmbeck, J. Rebizant, C. Scheppler and J.P. Glatz. "Electrochemical behaviour of plutonium ion in $\mathrm{LiCl}-\mathrm{KCl}$ eutectic melts." Journal of Electroanalytical Chemistry 561 (2004): 143-148.

[32] R.J. Lemire. Chemical thermodynamics of neptunium and plutonium. Vol. 4. Elsevier, 2001.

[33] R.J.M. Konings. "The ITU Material Property Data Base for f-elements and compounds, fMPD, Available from http." www. f-elements. net (2002).

[34] P. Masset, R.J. Konings, R. Malmbeck, J. Serp and J.P. Glatz. "Thermochemical properties of lanthanides ( $\mathrm{Ln}=\mathrm{La}, \mathrm{Nd})$ and actinides $(\mathrm{An}=\mathrm{U}, \mathrm{Np}, \mathrm{Pu}, \mathrm{Am})$ in the molten $\mathrm{LiCl}-\mathrm{KCl}$ eutectic. "Journal of Nuclear Materials 344.1 (2005): 173-179.

[35] J.O. Andersson, T. Helander, L. Höglund, P. Shi and B. Sundman. "Thermo-Calc \& DICTRA, computational tools for materials science." Calphad 26.2 (2002): 273-312.

[36] Mallett, J. J., et al. "Underpotential codeposition of $\mathrm{Cu}-\mathrm{Au}$ alloys." Electrochemical and solid-state letters 12.8 (2009): D57-D60.

[37] Alkire, R. C., Philip N. Bartlett, and Jacek Lipkowski. "Electrochemical engineering across scales: from molecules to processes." Advances in electrochemical science and engineering 15 (2015), p.86-87.

[38] J. Zhang. "Kinetic model for electrorefining, part II: Model applications and case studies." Progress in Nuclear Energy 70 (2014): 287-297.

[39] Thermo-Calc Software Database SSUB5, (Accessed 3/20/2016)

[40] R. Benz. "Thermodynamic properties of the system PuCl3-KCl", Dissertation, The University of New Mexico, 1958. 